\title{
Design Method of Hull Structure Model for Ultimate Strength Test
}

\author{
Huanxiang Sun ${ }^{1,2}$, Jin Gan ${ }^{2}$ \\ ${ }^{1}$ Key Laboratory of High Performance Ship Technology of Ministry of Education, Wuhan University of Technology, China \\ ${ }^{2}$ Departments of Naval Architecture, Ocean and Structural Engineering, School of Transportation, Wuhan University of Technology, China
}

\begin{abstract}
Based on the several practical research on real ship hull ultimate strength model test, a design method of hull structure model for ultimate strength test, which combine the numerical simulation analysis with a similar model design are proposed.
\end{abstract}

\section{Introduction}

Ships are large complex engineering structures. The ultimate strength of hull structure is considered as an important factor for evaluation of hull structure safety margin, and it must be checked in structure design and strength evaluation [1], [2]. There are two main methods, include numerical calculation and structural test, which are used to evaluate the ultimate strength of hull structure. Represented by Smith method and nonlinear finite element method, the numerical calculation has made abundant achievements [3], [4]. However, due to the complexity of hull structure and its load bearing, the numerical approach is hard to predict the ultimate strength of hull girder accurately. Consequently, the structure model experimental study is particularly important for ship engineering. The failure process is very complex, because hull girder is a complex space thin-walled structure. Through the model test of hull structure, the collapse process could be directly observed and its failure mechanism could be analysed [5], [6]. Additionally, the available experimental results could be used to verify and improve the accuracy and reliability of other numerical methods.

The ship structure laboratory of Wuhan University of Technology has been working on the hull structure strength tests for long time. Combined with model tests and numerical calculation methods, many experimental studies on the ultimate strength of various ship types, such as mono-hull ship, SWATH ship [7], Trimaran ship [8] and river-sea ship [9], have been completed in recent years. The test photos are shown in Fig. 1 to Fig. 4. Meanwhile, abundant research achievements have been obtained both in design and manufacture of similarity models, and the ultimate strength of several ships with special types have been predicted. In this paper, the design method of hull ultimate strength text model should be introduced in detail.

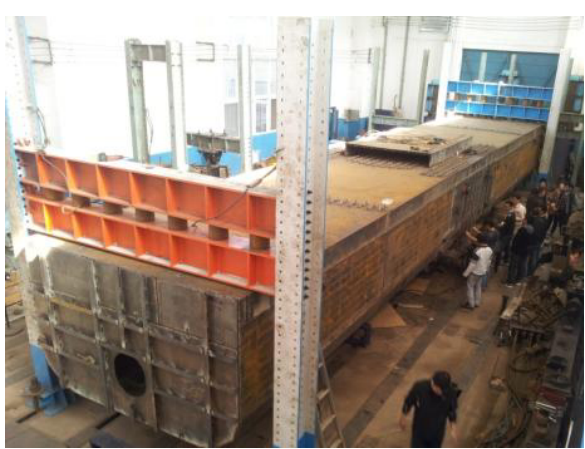

Figure 1. Experimental study on mono-hull ship.

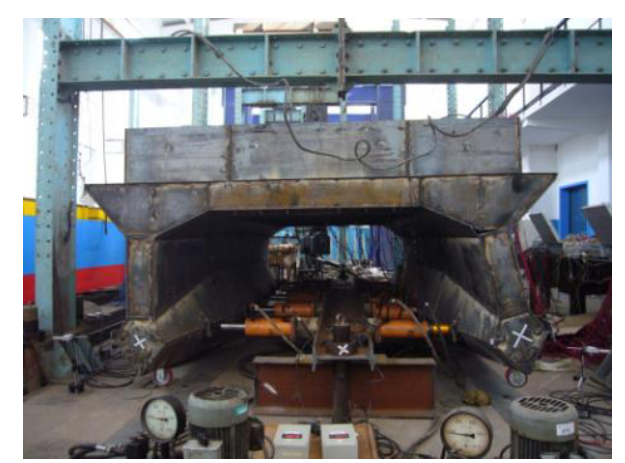

Figure 2. Experimental study on SWATH ship.

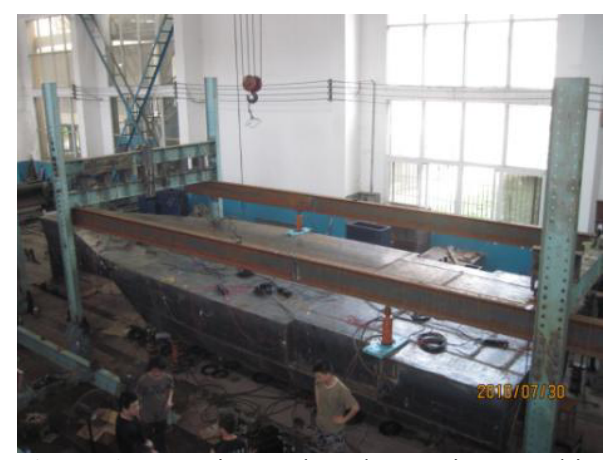

Figure 3. Experimental study on trimaran ship. 


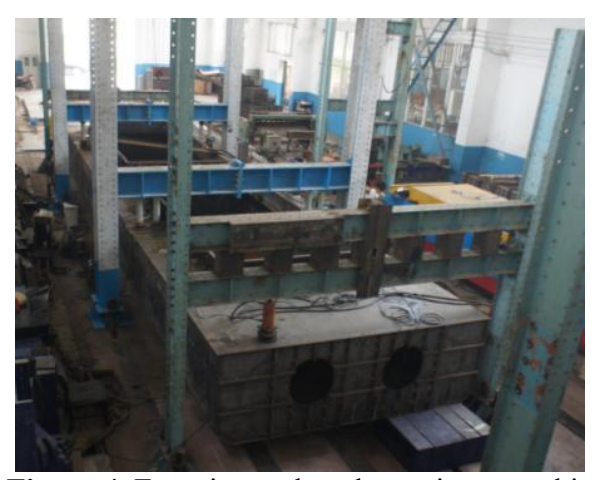

Figure 4. Experimental study on river-sea ship

\section{Similarity analysis of structural model}

The reliability and accuracy have been confirmed by a lot of experiments that setting the length $\mathrm{L}$ and thickness $\delta$ as the basic parameters in thin-walled structure modelling design. Usually, this kind of model is called distortion model. When design the ship hull ultimate strength experiment model, the length $\mathrm{L}$, thickness $\delta$ and force $\mathrm{F}$ are chose to be the basic physical quantities of dimensional analysis, therefore the basic dimensional system could be expressed as $[\mathrm{F}, \mathrm{L}, \delta]$. According to the characteristics of the ultimate strength of hull structure experiment, the similarity criterion relation in model design could be derived via dimensional analysis.

Due to the length dimensions $[\mathrm{F}]$ of the dimension matrix in the index of various physical quantities are zero. And modulus of elasticity $E$ is the intrinsic parameter of material and has no relationship with the external force. In this case, the value of the external force should not essential influence on the inner mechanism of the experiment. In the test condition, it is hard to make the load as same as the actual one, because the ships are subjected to the shear force and the bending moment under the real condition with the static water and the wave. Although the amplitude and the distribution of shear force and bending moment in the full range of ship could be got in the design phase, it is usually limited by test conditions to achieve this parabolic form distribution of the shear force and bending moment in the model. For load similarity, the load distribution is simplified to apply to the model in practice. For the boundary conditions similarity, the actual movement of the ship in water could not be simulated in the laboratory. Considering the factors above, in the model test, the way of model design is that guaranteeing the boundary as far as possible from the core area of the model, imposing the boundary conditions at both ends of the extended range, and $t$ minimizing the influence of boundary conditions on the experimental results according to the Saint-Venant principle.

\section{Structure model design}

\subsection{Scale cabin model design}

If the cabin model was designed based on several sections, the stiffness in different parts is variable, and a small scale will decrease the reliability and accuracy of model structure. So if we apply the bending load to the model, the buckling must be occurred in the part where it's structural strength weakest. But in actual situation, the buckling of real ship depends on specific load conditions of each section. So if we want to locate the dangerous section exactly, we should adopt multi-node loading to simulate the real load situation. Because of the complexity and uncertainties of the ultimate strength research, the selection of risky section of hull girder is one of the keys of the model design. Because of the complexity of the ship lines and structure, the section structures in different part vary greatly. Under different working conditions the load distribution along the ship will also be different, so we should calculate the ultimate strength of typical sections to identify the location of dangerous ones for the further design. Before determining the experimental cabin model, we could use numerical calculation method (Smith method, nonlinear finite element method) or standard method to identify dangerous sections of whole ship under different working conditions. The experimental cabin model could be obtained by extending the section, then four-point bend loading experiment could be conducted and the ultimate strength of the model could be observed. Furthermore, the real ship's capacity could be predicted. According to this method, we avoid experiment result error leading by the complexity of model. Also, numerical calculation method could be optimized according to the experiment results.

\subsection{Model similarity scale}

After determining the risky section, the structure design of the model section should be carried out under the condition of similarity criterion, which is the basic requirement of the general static strength model in structure design. Considering the characteristics of the ultimate strength, the size and number of bars of the stiffened plate should be rationally allocated in the scale model, which could ensure the stiffened plate grids have the approximate stability between the model and ship. Finally the model of the real ship section and the test section model could meet the similar conditions in the essence of the similar phenomenon. Considering the several factors such as the manufacture process of steel model, the actual purchase of plate models, the laboratorial loading capacity and the restrictions of field testing, the value of the similar thickness constant $\mathrm{C} \delta$ is suggested between $3: 1$ and $5: 1$, and the value of the similarity scale constant CL is suggested between 6:1 and 10:1 by the experience of hull structure model tests in our research team for years.

\subsection{Model structure design}

The most dangerous section of real ship is chosen to be the research object in test, and the test results could be used to predict the ultimate bending moment of the target section. In view of the above approach, the whole test model consists of one test section and two load sections, 
and the test load is four-point pure bending. The test section of model structure is designed as the dangerous section of real ship by the similarity theory. The load sections added at both ends of the test section could provide suitable loading and boundary conditions, and could ensure the accuracy of the test results.

By the conditions of similarity criterion, the section of real ship and model should meet the following similarity ratio:

$$
C_{I}=C_{L}^{3} C_{\delta}
$$

where $\mathrm{CI}$ is the ratio of section moment of inertia, CL is the similarity ratio of the section geometry and $\mathrm{C} \delta$ is the similarity ratio of the section thickness of real ship to model.

If the above similarity criterion is met, the section bending rigidity of real ship and model will be similar, which makes the same section deformation and curvature of real ship and model under similar bending moment. According to the assumption of plane section, the strain of profiles in different location is shown as follows:

$$
\varepsilon_{i}=\frac{y_{i}}{\rho}
$$

where $\varepsilon \mathrm{i}$ is the strains in different section area, yi is the distance between component and neutral axis in different section area and $\rho$ is the bending radius of curvature for hull girder.

According to the formula Eq. 1 and Eq. 2, the height of natural axis and the stress distribution of real ship and model must have the similarity ratio. The plate thickness in different locations has different thickness ratio, and the geometry sizes of section also meet the geometric similarity ratio. The preliminary determination of stiffeners sizes should satisfy the requirements as the following equation:

$$
C_{I}=C_{L}^{3} C_{\delta}=\frac{I_{g s}}{I_{g m}}
$$

where Igs is the section moment of inertia for stiffeners with ribband in real ship, and Igm is the section moment of inertia for stiffeners with ribband in test model.

In accordance with the model section design criteria above, the model section structure could be designed according to the type and size of the dangerous section of real ship structure. On this basis, the test section, transition section and load section of ship hull girder test can be designed.

\section{Model processing technology}

Since the hull structure model is a complex thin-walled structure, the model processing precision affects the result of the test directly, especially has a greater influence to the testing results. Therefore, the hull model should be conducted on high precision processing platform. In the process of machining, undeserved technological process and processing method could affect the precision of the model. For guaranteeing the precision of hull model, several measures are advised as follows:

All components of the test model are trying to use shear or frilled edge process, and less to use cutter knife and welding set.

Prefabricate and correct the shell parts and internal frames, and choose the proper assembly procedures which need to control the welding procedure strictly on the assembly platform.

Lines lofting and frame assembly should be located strictly in the process. Minimize the weld length under the premise of reliable connection and effective force transfer, and select the effective electrode and the best welding current at the same time.

Conduct dimensional checks in every working procedure during the components assembling, and correct the detected problems timely.

\section{Conclusions}

Structure model design and manufacture are vital to the ultimate strength test of hull structures. The ship hull structure models are designed by the method, which combined numerical calculation and structural similarity analysis, have been applied to ultimate strength model tests and the similarities prediction of real ships successfully. The method has been used effectively to evaluate the ultimate strength of ship structures. Due to the complexity of ultimate strength problem for ship structures, the study is not completed yet and more work need to be done.

The similarity model is designed based on the linear elastic theory, but the structure model of ultimate strength test involves the geometrical nonlinearity and material nonlinearity, so, the conversion from the experimental result to real ship is the main problem need to overcome in further study.

With the development of ship type and the application of new material, the ultimate strength problem of ship structure should become more and more complex. Considering the coupled effects longitudinal bending, transverse bending and torsion, the ultimate strength of hull structure still need our further study.

\section{References}

1. Vasta J: Lessons learnt from full-scale ship structural test, Trans. SNAME, 1958, 66:165-243.

2. Sugimura T, NoZaki M, SuZuki T: Destructive experiment on ship hull model under longitudinal bending, Journal of the Society of Naval Architects of Japan, 1966, 119: 209-220.

3. Caldwell J B: Ultimate longitudinal strength, Trans RINA, 1965, 107: 411-430.

4. Chen Y K, Kutt L M, Piaszezyk C M, et al: Ultimate strength of ship structures, Trans.SNAME, 1983: 149-168.

5. Hughes O F: Ship structural design: a rationallybased, computer-aided, optimization approach, New York: Wiley, 1983. 
6. Bai Y, Bendiksen E: Collapse analysis of ship hulls, Marine Structures, 1993, 6: 485-507.

7. Liu Bin, Wu Weiguo and Huang Yanling: Ultimate strength test study of SWATH ships, Proceedings of the Nineteenth International Offshore and Polar Engineering Conference (2009).

8. Wu Weiguo, Xu Shuangxi and Liu Weiqin: Study on the ultimate strength test of high speed trimaran,
Proceedings of the 3rd International Conference on Marine Structures (2011).

9. Wu, Haochen, $\mathrm{Wu}$, Weiguo, Gan, Jin and Sun Huanxiang: Ultimate strength analysis of a river-sea ship under combined action of torsion and bending, 32nd International Conference on Ocean, Offshore and Arctic Engineering (2013). 